$10-2015$

\title{
Filling the Google Gaps: Harnessing the power of Google through Instruction
}

Rebecca Mattson

Penn State Law, ram6023@psu.edu

Follow this and additional works at: http://elibrary.law.psu.edu/library_faculty

Part of the Legal Education Commons, and the Legal Writing and Research Commons

\section{Recommended Citation}

Mattson, Rebecca, "Filling the Google Gaps: Harnessing the power of Google through Instruction" (2015). Law Library Faculty Works. 12.

http://elibrary.law.psu.edu/library_faculty/12 


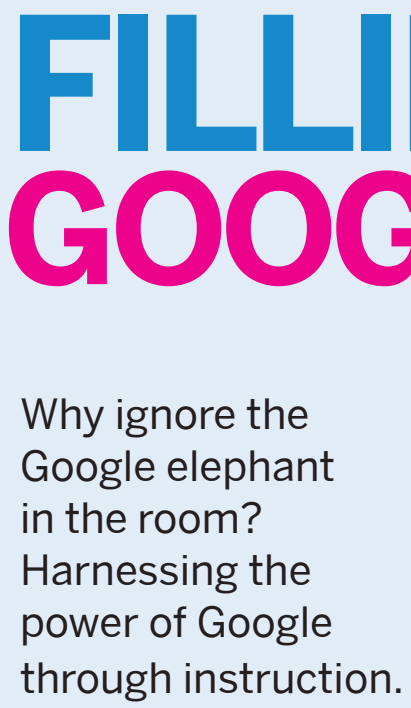

BY REBECCA MATTSON

Ask any first-year (or maybe even second- and thirdyear) student or associate where they begin to look for information, and the most likely response is "Google." As librarians, many of us tend to urge our students not to use Google because of its faults. Our tendency to discourage the use of Google is, at least in part, warranted. Studies, such as the ERIAL (Ethnographic Research in Illinois Academic Libraries) project, show that while students may believe they know how to effectively research on Google, they consistently fail to limit search results to achieve a narrower pool of more relevant results and, perhaps more critically, do not understand that there may be gaps in their Google research that a librarian can help fill. The findings of the ERIAL project are detailed in Steve Kolowich's article "What Students Don't Know," published in Inside Higher Ed on August 22, 2011.

\section{NG THE LE}
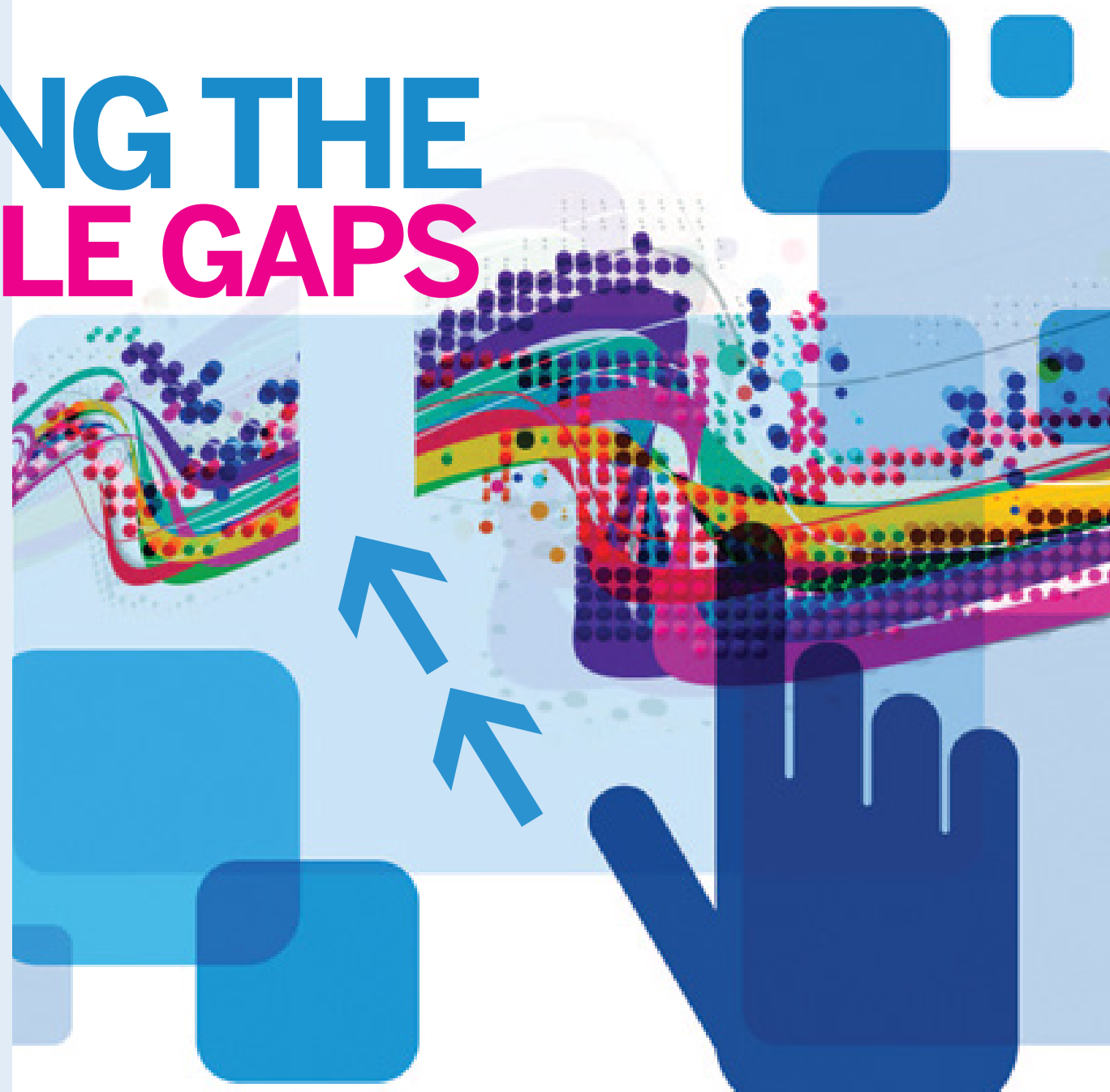

titcos

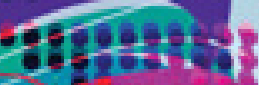
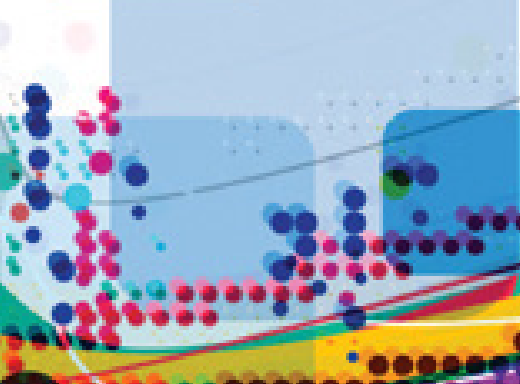

a *
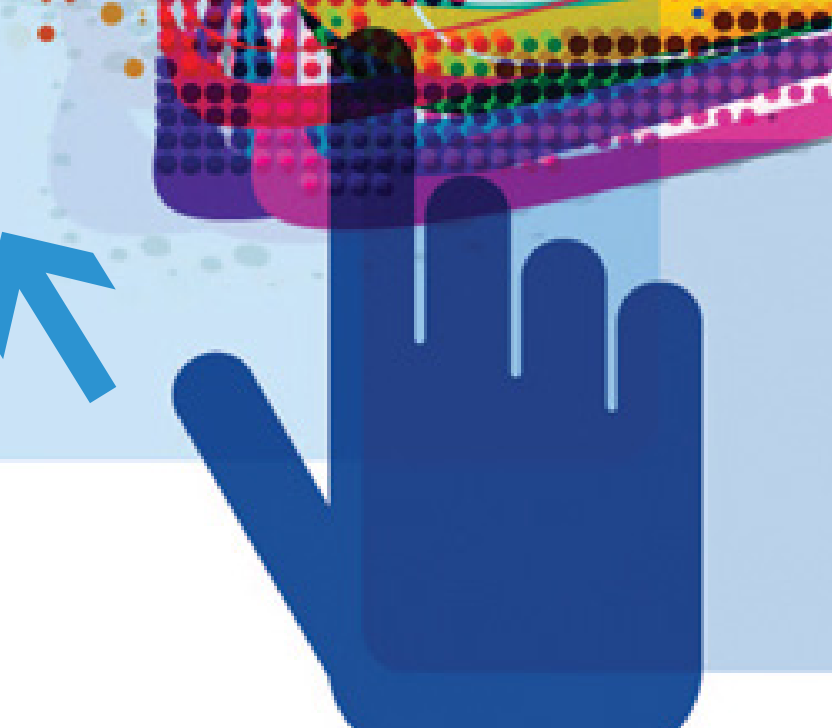

\section{"Students ...} do not understand there may be gaps in their Google research that a librarian can help fill."

Google can, however, be a powerful tool when taught and used correctly. Instead of ignoring the Google elephant in the legal research classroom, we ought to admit that our students are going to use it and teach them how to do so effectively. By teaching students how to use Google, we are helping to create a generation of internet-savvy, cost-effective researchers.
Google Advanced Search Librarians prefer Boolean searching to keyword searching when conducting serious legal research. When using a service such as Lexis Advance or WestlawNext, we can construct efficient Boolean queries that narrow down our results to a manageable number of cases or articles. When law students first encounter the "big box" and enter keywords, they are granted the entire universe of legal research. When they put the same words in Google, the results are even more overwhelming: thousands of results that may or may not be law-related and are not vetted for reliability.

Many young attorneys and law students are not aware that Google is, in fact, capable of running a terms and connectors search as well. Clearly, one search is more effective than the other, especially when cost is factored. When we teach our students how to use Boolean searching in Lexis or Westlaw, we should also be teaching them how to use Google's advanced search to narrow results.

Using the pre-created fields on advanced search at www.google.com/ advanced_search, a student can search the Google 
equivalent of "and," "or," "exact phrase," and "not." One simple example shows the clear advantage of using advanced search.

A user searching on advanced search for "dog bite" as an exact phrase retrieves 808,000 results, while a user simply entering the words "dog bite" without quotations retrieves $15,700,000$ results. The 888,000 is still unmanageable, but it's certainly better than nearly 16 million!

From the advanced screen, the user can further narrow the search by type of site, such as .edu, .gov, or .org. This will increase the credibility of the results. The same "dog bite" phrase search limited to .edu sites brings the total number of results down to 9,190. More experienced users can simply indicate the limiter in the search box: "site:edu (dog bite)."

Google's search operators also allow users to drill down further with their searching. A user can use the operator "related" to find a website that is similar to a site they already know. For example, if you enter "related:time. com" into the search box, it returns similar breaking news websites, such as CBS News, The Christian Science Monitor, and The Atlantic.

\section{Google Scholar}

Google first launched Scholar in November 2004 as a platform for researchers to search scholarly literature. In 2009, Google began making legal cases available for researchers, and users are also able to search for patents (more on this shortly). A searcher using Google Scholar, which is available at https://scholar.google.com, can find not only citations to legal scholarly journal articles available through institutional or personal subscriptions, but also links to full-text downloadable articles. As many law reviews move to an open-source model and upload archived content, the ability to discover these articles becomes more valuable.

Google Scholar also offers a "My Library" link-saving option, similar to the foldering capabilities of WestlawNext and Lexis Advance, so the user can save a citation into the library to access at a later date. The option to save appears below the description of the document, alongside related articles and citation metrics. A researcher can limit the search in Scholar by author, which will return all Google-indexed articles written by that author (and possibly another author with a similar name or first initial).

Google Scholar's ability to limit a search to case law is extremely helpful, and the results are much more meaningful than those retrieved by running the same search in Google. For instance, if a searcher selects the "Case Law" option and searches "hearsay evidence," the number one result is Crawford v. Washington. Once inside the document, there is a "How Cited" option, which shows cases that are related, cases that cite the original case, and some examples of quotes from cases citing the original case. "How Cited" does not use signals or flags to indicate type of treatment, nor does it indicate depth of treatment. The researcher must read the cases listed to determine the kind of treatment the case has been given. A good example is Bowers $v$. Hardwick, which was overturned in 2003 by Lawrence v. Texas. Lawrence is listed as the first case under "cited by," but the quote from Lawrence is fourth on the list of examples of treatment, and the quote used does not convey that it was actually overruled.

\section{Google Patents}

Google Patents, at https://patents. google.com, launched in 2006, but a recent update integrated the patent search with Scholar. The search box on Google Patents includes a check-box to include non-patent literature and prior art. When that box is checked, Google also searches using Scholar to find related literature and prior art. To search for a patent, a researcher can either search by patent or application number or use a keyword or advanced search.

\section{SMOOTH OPERATORS}

\section{THESE SEARCH TRICKS CAN HELP STUDENTS AND ASSOCIATES IMPROVE GOOGLE SEARCH RESULTS}

\begin{tabular}{|l|l|}
\hline OPERATOR & HOW TO USE IT \\
\hline site: & $\begin{array}{l}\text { Get results from certain sites or do- } \\
\text { mains.Examples: olympics site:nbc. } \\
\text { com and olympics site:.gov }\end{array}$ \\
\hline link: & $\begin{array}{l}\text { Find pages that link to a certain } \\
\text { page. Example: link:youtube.com }\end{array}$ \\
\hline related: & $\begin{array}{l}\text { Find sites that are similar to a } \\
\text { web address you already know. } \\
\text { Example: related:time.com }\end{array}$ \\
\hline OR & $\begin{array}{l}\text { Find pages that might use one of } \\
\text { several words. Example: marathon } \\
\text { OR race }\end{array}$ \\
\hline info: & $\begin{array}{l}\text { Get information about a web ad- } \\
\text { dress, including the cached version } \\
\text { of the page, similar pages, and } \\
\text { pages that link to the site. } \\
\text { Example: info:google.com }\end{array}$ \\
\hline cache: & $\begin{array}{l}\text { See what a page looks like the last } \\
\text { time Google visited the site. } \\
\text { Example: cache:washington.edu }\end{array}$ \\
\hline
\end{tabular}

Note: When you search using operators or punctuation marks, don't add any spaces between the operator and your search terms.

Priming Effective Researchers Students and associates are going to use Google for at least some research regardless of what they learn in Legal Research class. As educators and librarians, we are in the position to teach them how to use Google effectively as a free resource. $\$$

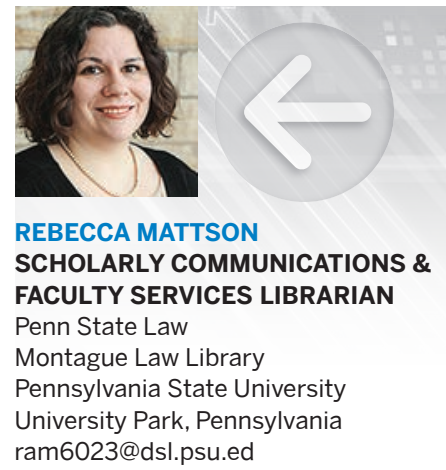

